\title{
Direct Chemisorption-Assisted Nanotransfer Printing with Wafer-Scale Uniformity and Controllability
}

Zhi-Jun Zhao ${ }^{a \neq}$, Sang-Ho Shin ${ }^{b \neq}$, Sang Yeon Lee ${ }^{b}$, Bongkwon Son $^{b}$, Yikai Liao ${ }^{b}$, Soonhyoung Hwang ${ }^{c}$, Sohee Jeonc ${ }^{c}$ Hyeokjoong Kang ${ }^{c}$, Munho Kim ${ }^{b^{*}}$, and Jun-Ho Jeong ${ }^{c^{*}}$

anstitute of Smart City and Intelligent Transportation, Southwest Jiaotong University, No. 999

Pidu District, Chengdu, Sichuan, China

${ }^{\mathrm{b} S}$ Shool of Electrical and Electronic Engineering, Nanyang Technological University, 50

Nanyang Avenue, Singapore 639798

${ }^{c}$ Nano-Convergence Mechanical Systems Research Division, Korea Institute of Machinery and Materials, 156, Gajeongbuk-ro, Yuseong-gu, Daejeon 34103, South Korea

†Equal contribution

* Corresponding authors 
(a)
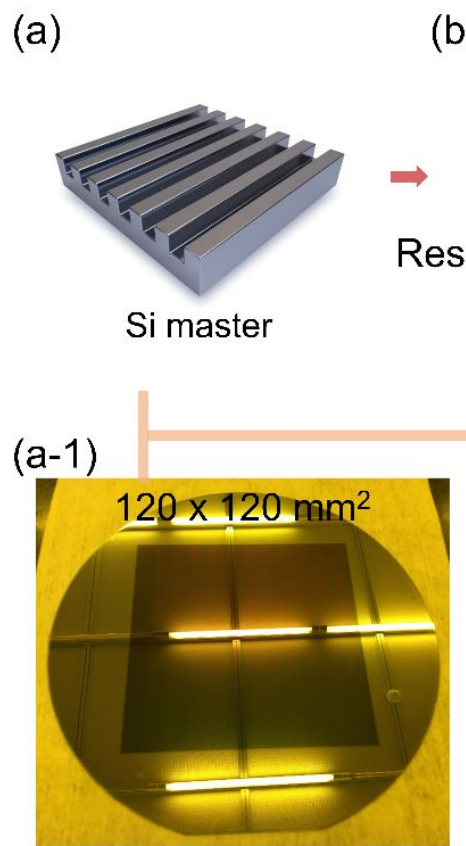

Si master (b)

(b)

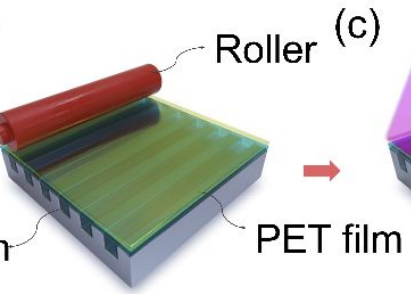

Nanoimprint (c)

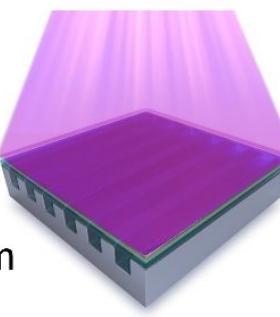

UV-curing (d) Polymer mold

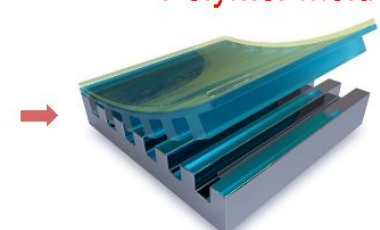

detachment

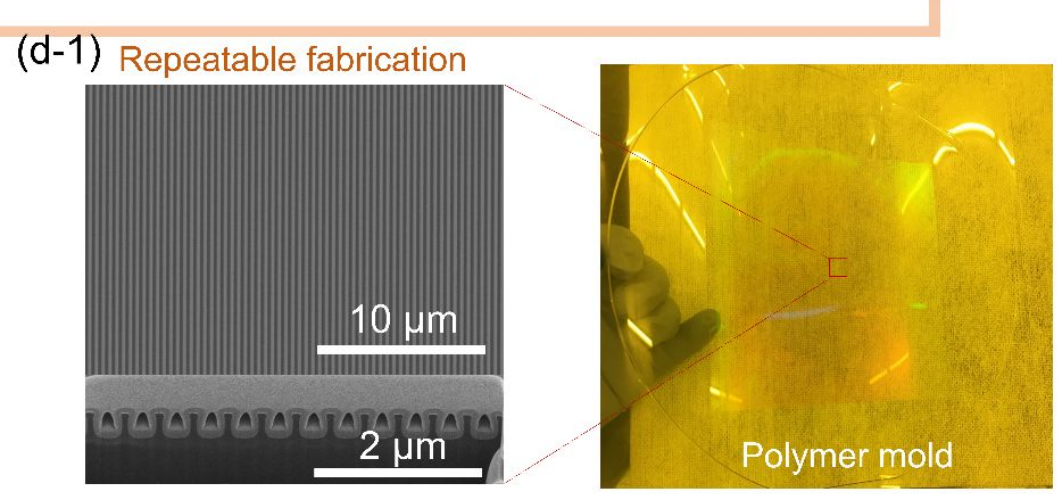

Figure S1. Schematic fabrication process of the polymer mold. (a) Preparation of the Si master with nanopatterns. (a-1) Photograph of the Si master with line patterns across an area of $120 \times 120 \mathrm{~mm}^{2}$. (b) Nanoimprint process using a roller for the resin to be fully infiltrated into nanopatterns. (c) UV-curing process. (d) Detachment process. (d-1) Photograph, top-view SEM, and cross-sectional FIB images of the polymer mold.

Repeatable fabrication process: First, a Si master with nanopatterns was prepared via conventional $\mathrm{KrF}$ lithography. To easily separate the polymer mold from the Si master, self-assembled monolayer (SAM) treatment was performed at $80^{\circ} \mathrm{C}$ for $25 \mathrm{~min} .{ }^{1,2}$ Trichloro( $1 \mathrm{H}, 1 \mathrm{H}, 2 \mathrm{H}, 2 \mathrm{H}$-perfluorooctyl)silane was selected as the SAM treatment material (Sigma-Aldrich). Second, a RM-311 resin with a low surface energy was coated onto the Si master. Then, a polyethylene terephthalate (PET) film was covered onto the surface of the resin, and uniform pressure was applied using a nanoimprint roller. Third, UV curing was performed to fully polymerise the resins. Finally, the detachment process was implemented to obtain a polymer mold with nanopatterns. The Si master could be repeatedly used to replicate the 
polymer mold. 

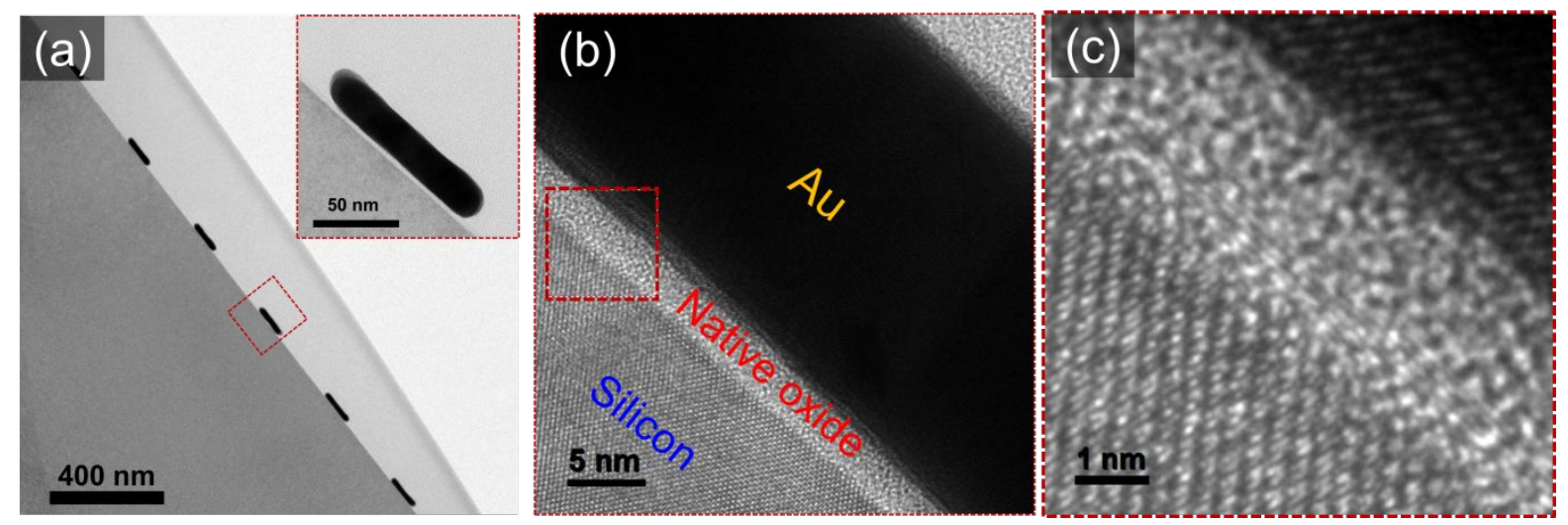

Figure S2. Cross-sectional HRTEM images of the Au nanostructures on the Si substrate. (a) Lowmagnification TEM image for clearly observing the nanostructures after transfer printing. (b) Interface between the Au layer, native oxide layer, and Si substrate. (c) Crystalline structures of Au, native oxide, and Si composition. 
(a)
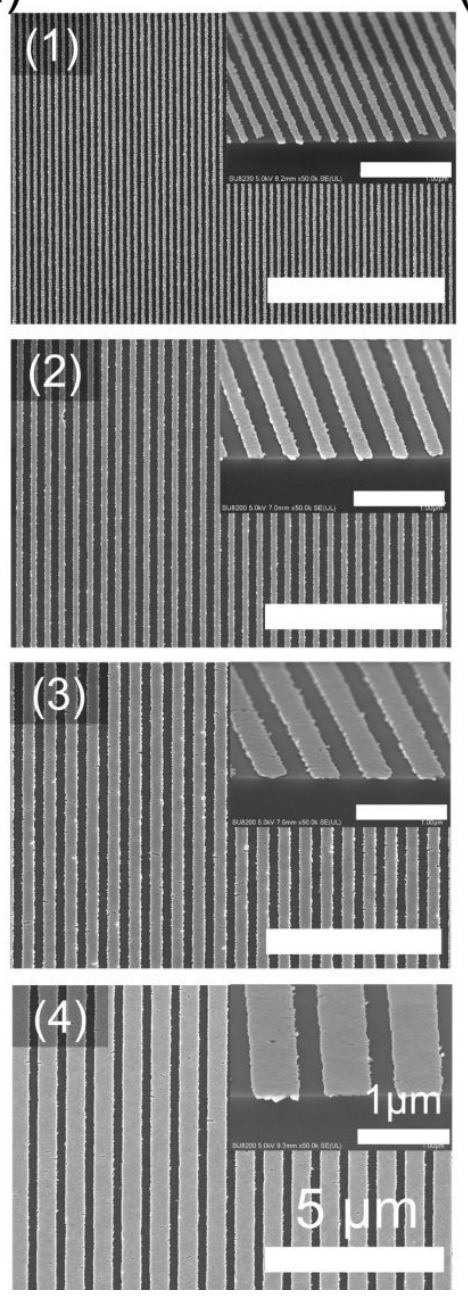

(b)
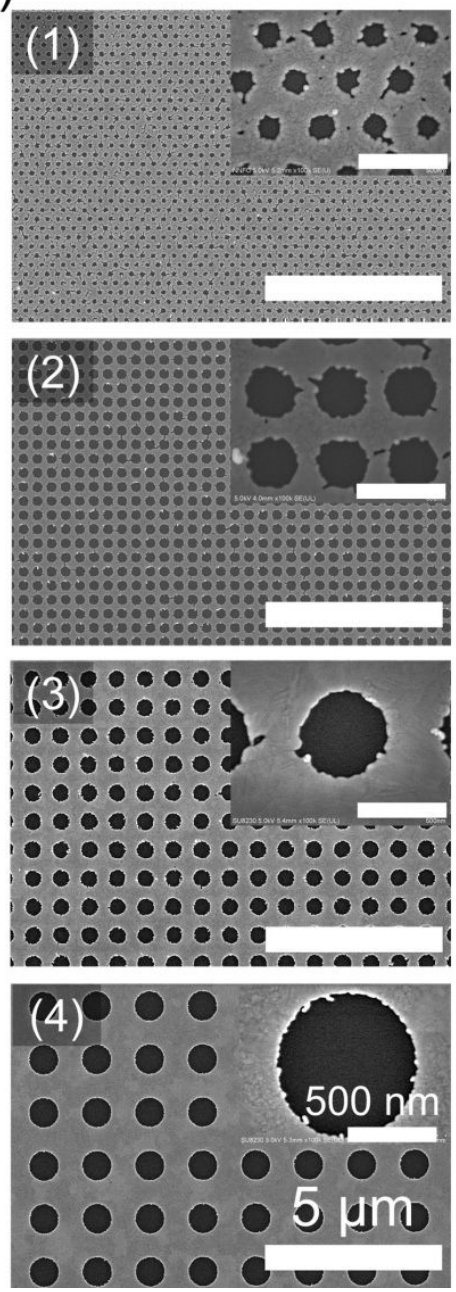

(c)
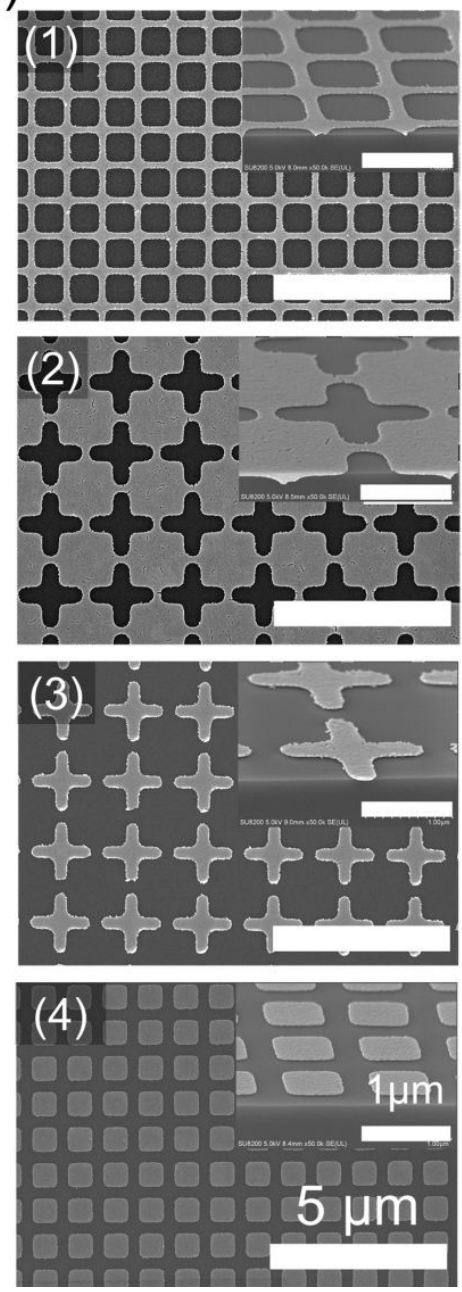

Figure S3. SEM images of the transfer-printed Au nanopatterns on Si substrates via EB-nTP. (a) Au line patterns with different dimensions (width/spacing/thickness). (1) $100 / 100 / 20 \mathrm{~nm}$. (2) $200 / 200 / 20$ nm. (3) $400 / 200 / 20 \mathrm{~nm}$. (4) $600 / 200 / 20 \mathrm{~nm}$. (b) Au nanomeshes with various dimensions (diameter/pitch/thickness). (1) $100 / 300 / 20 \mathrm{~nm}$. (2) $200 / 400 / 20 \mathrm{~nm}$. (3) $400 / 800 / 20 \mathrm{~nm}$. (4) $750 / 1500 / 20$ nm. (c) Various Au nanostructures. (1) Au nanomeshes with dimensions of $800 \mathrm{~nm}$ (width) $\times 800 \mathrm{~nm}$ (length) $\times 20 \mathrm{~nm}$ (thickness). (2) Micro-cross holes $(1.4 \mu \mathrm{m} \times 1.8 \mu \mathrm{m})$. (3) Micro-cross dots $(1.4 \mu \mathrm{m} \times$ $1.8 \mu \mathrm{m}$ ). (4) Square nanodots (width: $800 \mathrm{~nm}$, pitch: $1000 \mathrm{~nm}$ ). Scale bars for the main figures and insets denote $5 \mu \mathrm{m}$ and $1 \mu \mathrm{m}$, respectively. 
Optimisation of the CF-nTP process: It was hypothesised that the thickness, pressure, temperature, and time played a major role in the reliable transfer printing of nanopatterns. Therefore, we sought to understand the effects of the temperature, time, pressure, and thickness on the CF-nTP process. Ordered $\mathrm{Au}$ line pattern arrays with dimensions of 200 (width) $\times 400$ (pitch) $\times 20 \mathrm{~nm}$ (thickness) were chosen to optimise the CF-nTP conditions. First, we varied the bonding temperatures in the $120-200{ }^{\circ} \mathrm{C}$ range with $20^{\circ} \mathrm{C}$ steps under a constant pressure and bonding time of 3 bar and $1 \mathrm{~min}$, respectively (Fig. S4). As shown in Figure S4, the CF-nTP of the Au line patterns failed when the temperature was 120 and $140{ }^{\circ} \mathrm{C}$ because the surface of the $\mathrm{Au}$ line patterns in contact with the substrates could not be melted, resulting in failed bonding at the interface. This was consistent with the results of previous studies, ${ }^{3-5}$ which reported the thickness dependence of the melting point of noble metals at the nanoscale. The CFnTP of the Au line patterns was achieved when the temperature was $160{ }^{\circ} \mathrm{C}$; however, no Au line patterns were transfer-printed in some areas because of the short bonding time and low pressure (Fig. S4(3)), which could not provide effective contact and sufficient melting time at the interface between the $\mathrm{Au}$ and Si substrate. The optimised temperature was $160{ }^{\circ} \mathrm{C}$ for the 20 -nm-thick Au line patterns because; as observed, most of the regions showed good transfer printing of the Au line patterns. Second, we modified the bonding pressure (1, 3, and 5 bar) and time $(1,3,5,7$, and $10 \mathrm{~min})$ at a bonding temperature of $160{ }^{\circ} \mathrm{C}$, indicating that all Au line patterns were transfer-printed (Figs. S5 and S6). However, the morphologies of the Au line patterns changed depending on the bonding pressure and time during the CF-nTP process. Lastly, we varied the thickness of the Au nanopatterns in the range of 20-40 nm with $10 \mathrm{~nm}$ steps at different temperatures of 160,180 , and $200{ }^{\circ} \mathrm{C}$ (Fig. S7). As shown in Figure S7, a print yield in excess of $99.7 \%$ was achieved at a bonding temperature of $160{ }^{\circ} \mathrm{C}$ when the $\mathrm{Au}$ thickness was $20 \mathrm{~nm}$. However, it significantly reduced to $67.55 \%$ and $3.16 \%$ when the thickness of the Au nanopatterns was 30 and $40 \mathrm{~nm}$, respectively. Although the bonding temperatures of 180 and $200{ }^{\circ} \mathrm{C}$ increased the print yield back to $99 \%$ at a $30 \mathrm{~nm}$ thickness, the print yields were in the range of $74 \%$ and $55 \%$, respectively, when the Au thickness was $40 \mathrm{~nm}$. The observed trend was mainly attributed to the thickness-dependent melting temperatures of the Au layer at the nanoscale. ${ }^{3-5}$ 

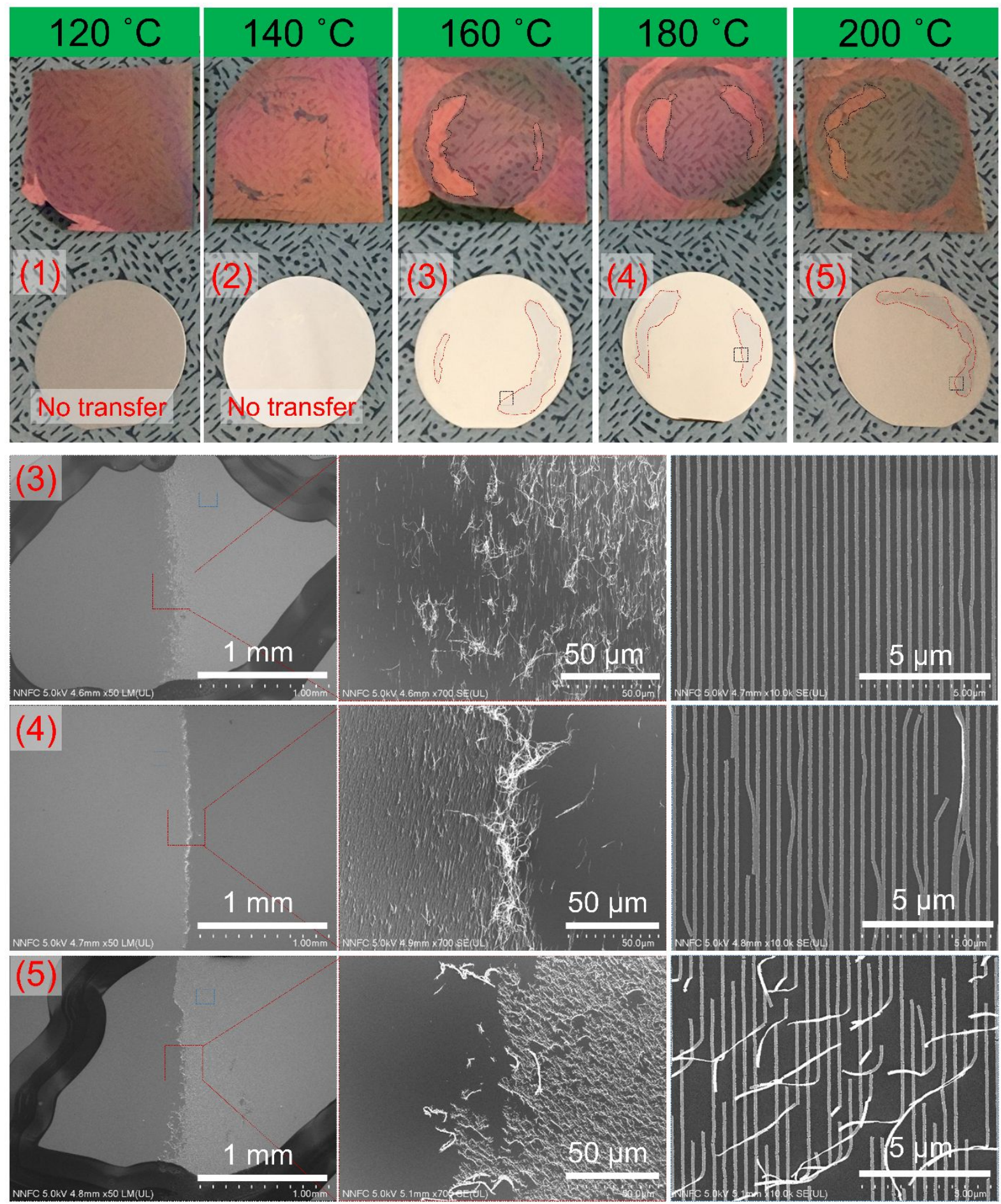

Figure S4. Photographs and top view SEM images of the Au nanopatterns that were transfer-printed onto 2-inch Si substrates under different heating temperatures, at a constant pressure of 3 bar, and a heating time of $1 \mathrm{~min}$ : (1) $120^{\circ} \mathrm{C}$, (2) $140{ }^{\circ} \mathrm{C}$, (3) $160^{\circ} \mathrm{C}$, (4) $180^{\circ} \mathrm{C}$, (5) $200{ }^{\circ} \mathrm{C}$. 


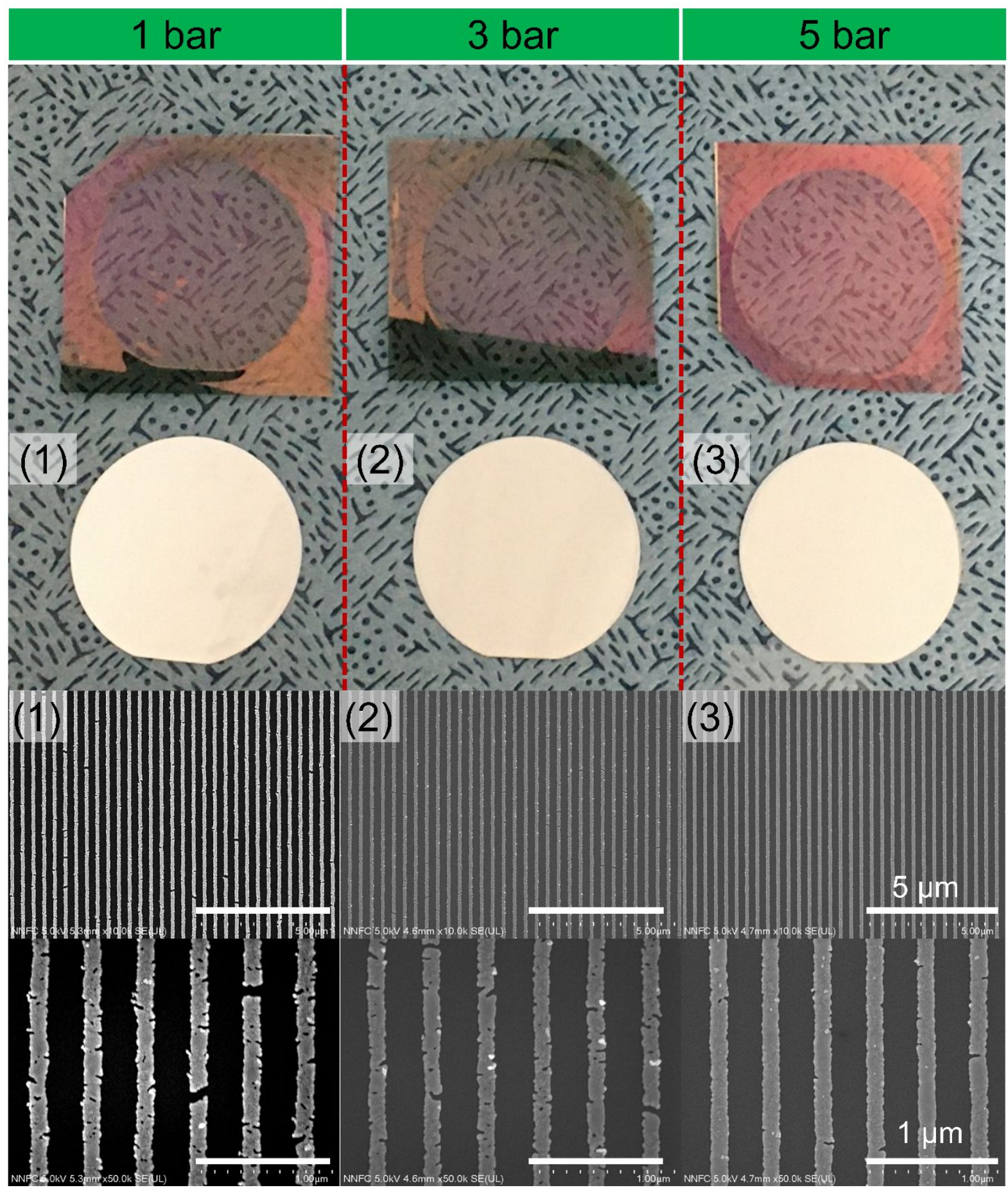

Figure S5.Photographs and top view SEM images of the Au nanopatterns that were transfer-printed onto 2-inch Si substrates under different pressures, a constant heating temperature of $160^{\circ} \mathrm{C}$, and a heating time of 5 min at: (1) 1 bar, (2) 3 bar, (3) 5 bar. 

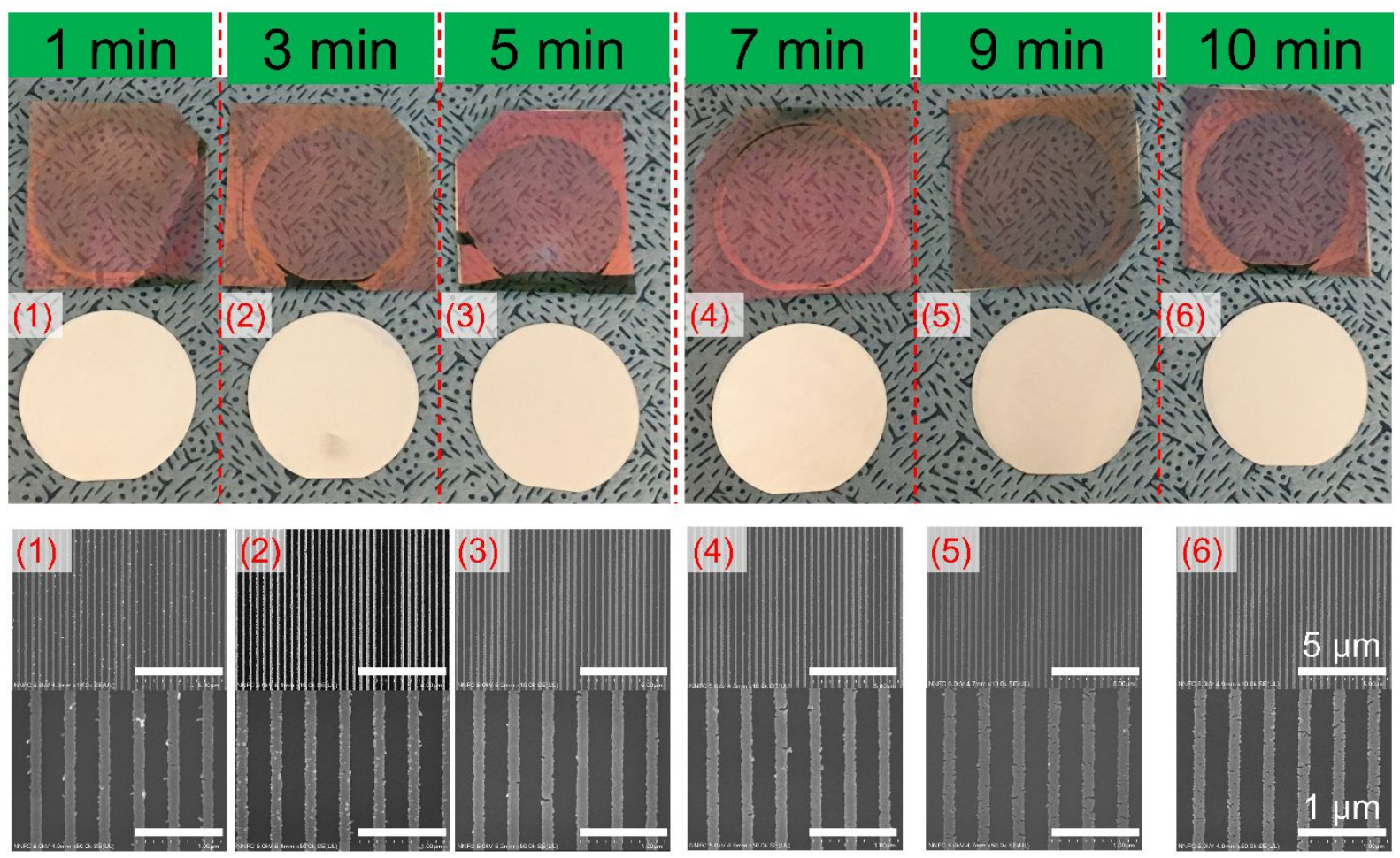

Figure S6. Photographs and top-view SEM images of the Au nanopatterns that were transfer-printed onto 2-inch Si substrates under different heating times, a constant heating temperature of $160^{\circ} \mathrm{C}$, and a pressure of 5 bar for: (1) $1 \mathrm{~min}$, (2) $3 \mathrm{~min}$, (3) $5 \mathrm{~min}$, (4) $7 \mathrm{~min}$, (5) $9 \mathrm{~min}$, (6) $10 \mathrm{~min}$. 


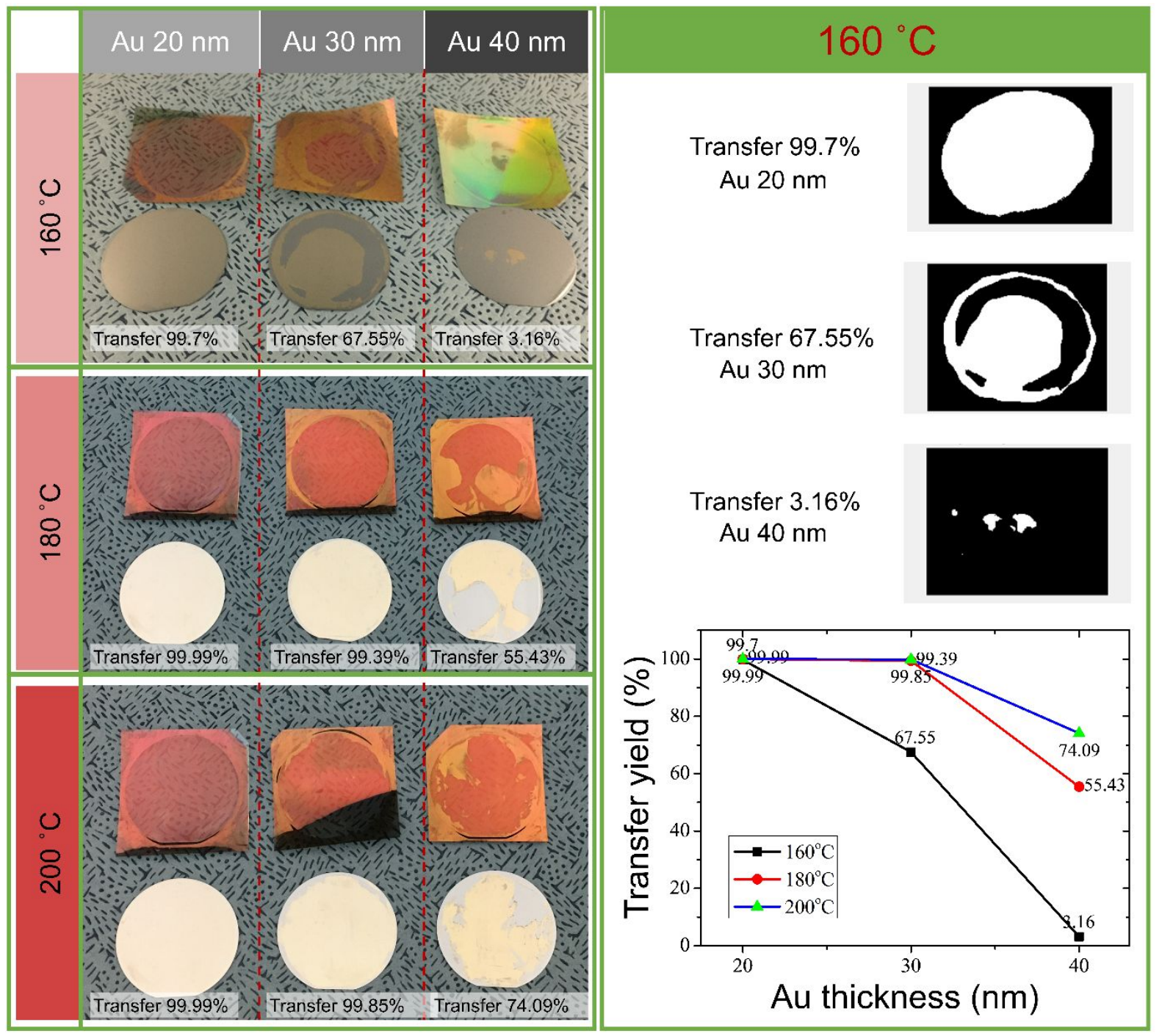

Figure S7. Evaluation of transfer print yield depending on the thickness of the Au nanopatterns from $20-40 \mathrm{~nm}$ with $10 \mathrm{~nm}$ steps under different temperatures of 160,180 , and $200^{\circ} \mathrm{C}$. 


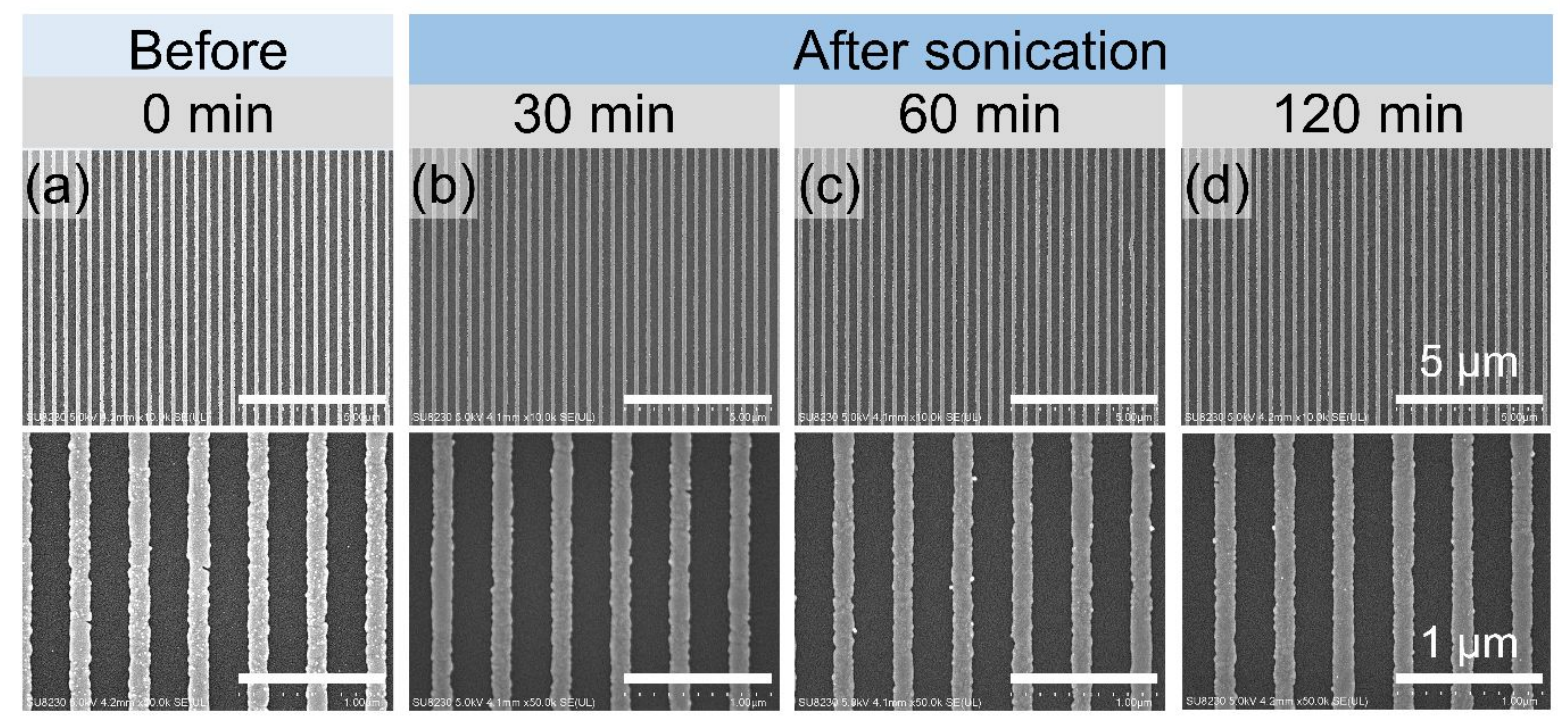

Figure S8. Top view, SEM images of the Au line patterns that were transfer-printed onto the Si substrate (a) before and (b-d) after sonication in acetone for 30, 60, and 120 min, respectively.
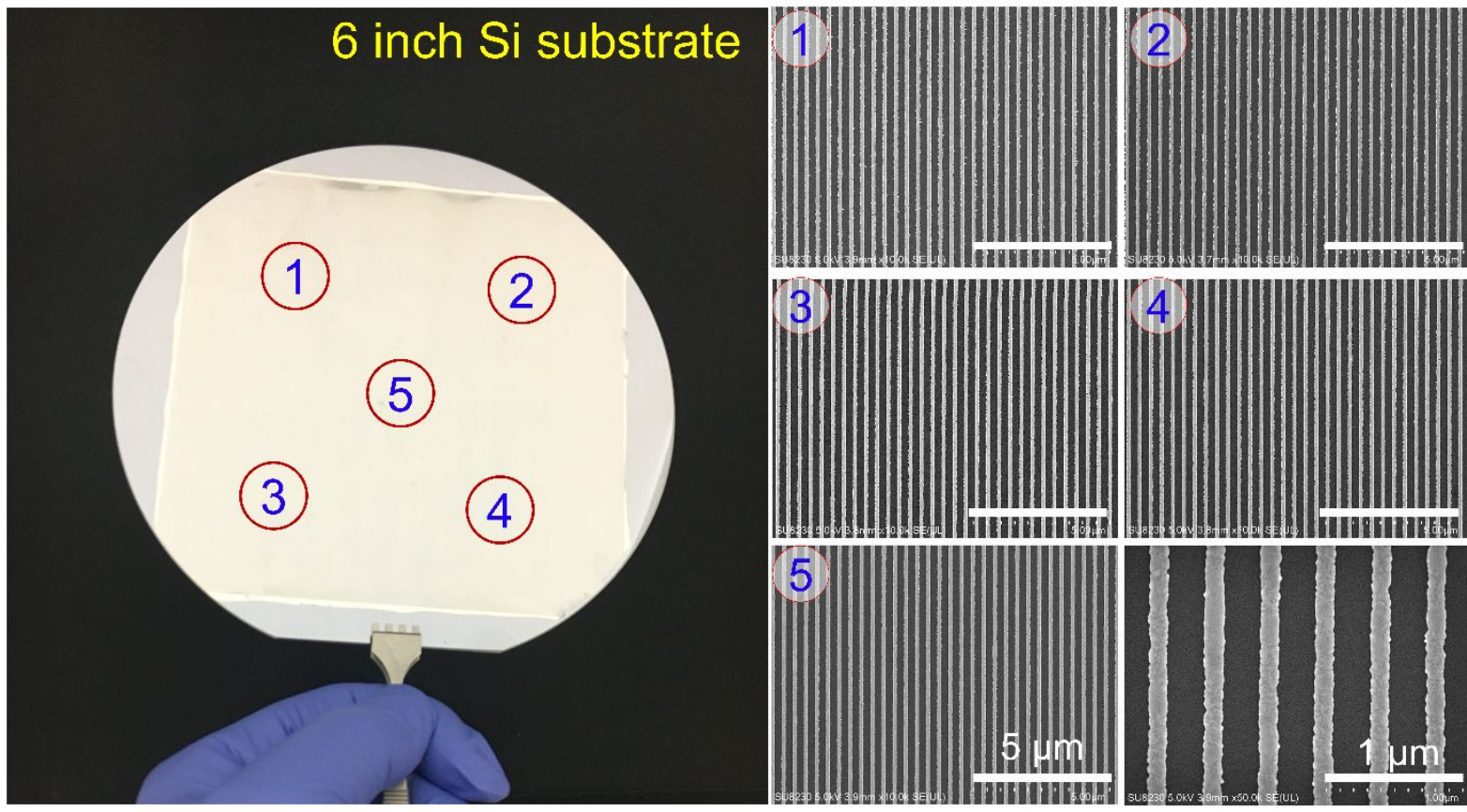

Figure S9. Photograph and top view SEM images of Au line patterns with dimensions of 200 (width) $\times$ 200 (space) $\times 20 \mathrm{~nm}$ (thickness), transfer-printed onto a 6-inch Si substrate, indicating the great uniformity of the Au line patterns. SEM images were taken from five different areas. 

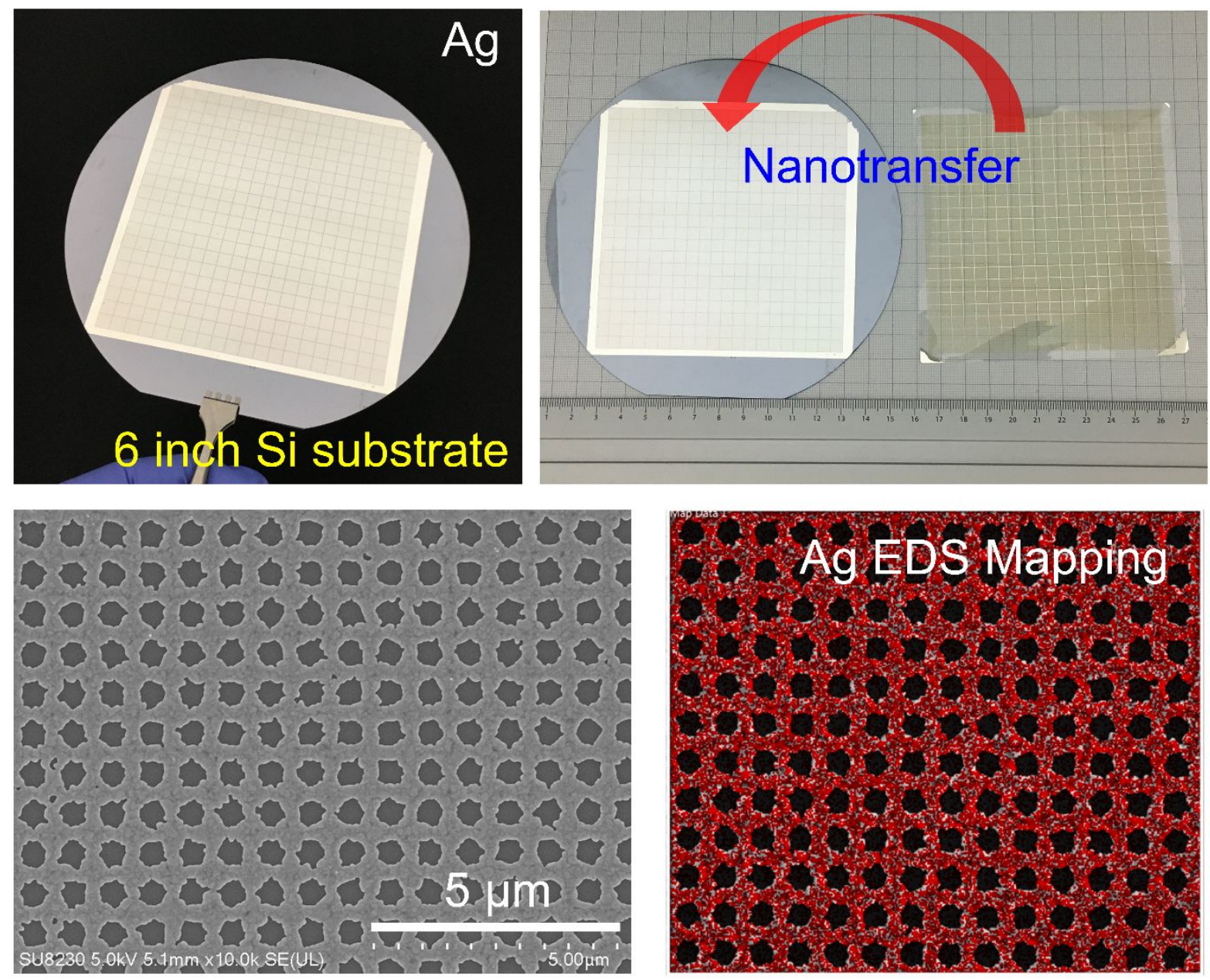

Figure S10. Photographs, top view SEM, and EDS mapping images of Ag nanomeshes with a diameter of $400 \mathrm{~nm}$ and pitch of $800 \mathrm{~nm}$, transfer-printed onto a 6-inch Si substrate at a pressure of 5 bar, heating temperature of $160^{\circ} \mathrm{C}$, and heating time of $5 \mathrm{~min}$. 


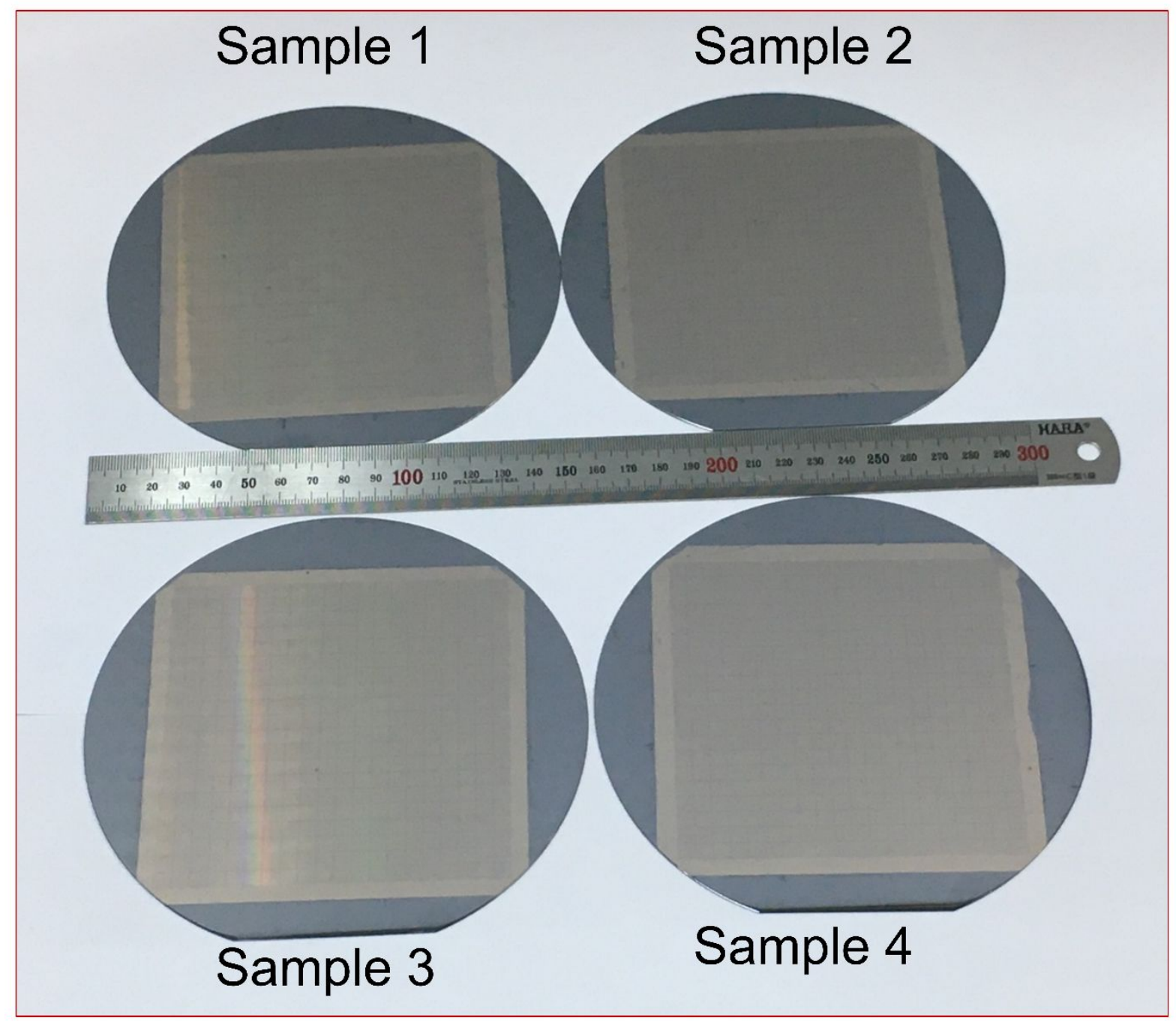

Figure S11. Photograph of four, 6-inch, Si substrates with Au nanomeshes (diameter: 400nm, pitch: $800 \mathrm{~nm}$ ), indicating the reproducibility of our method. CF-nTP was performed consecutively. 


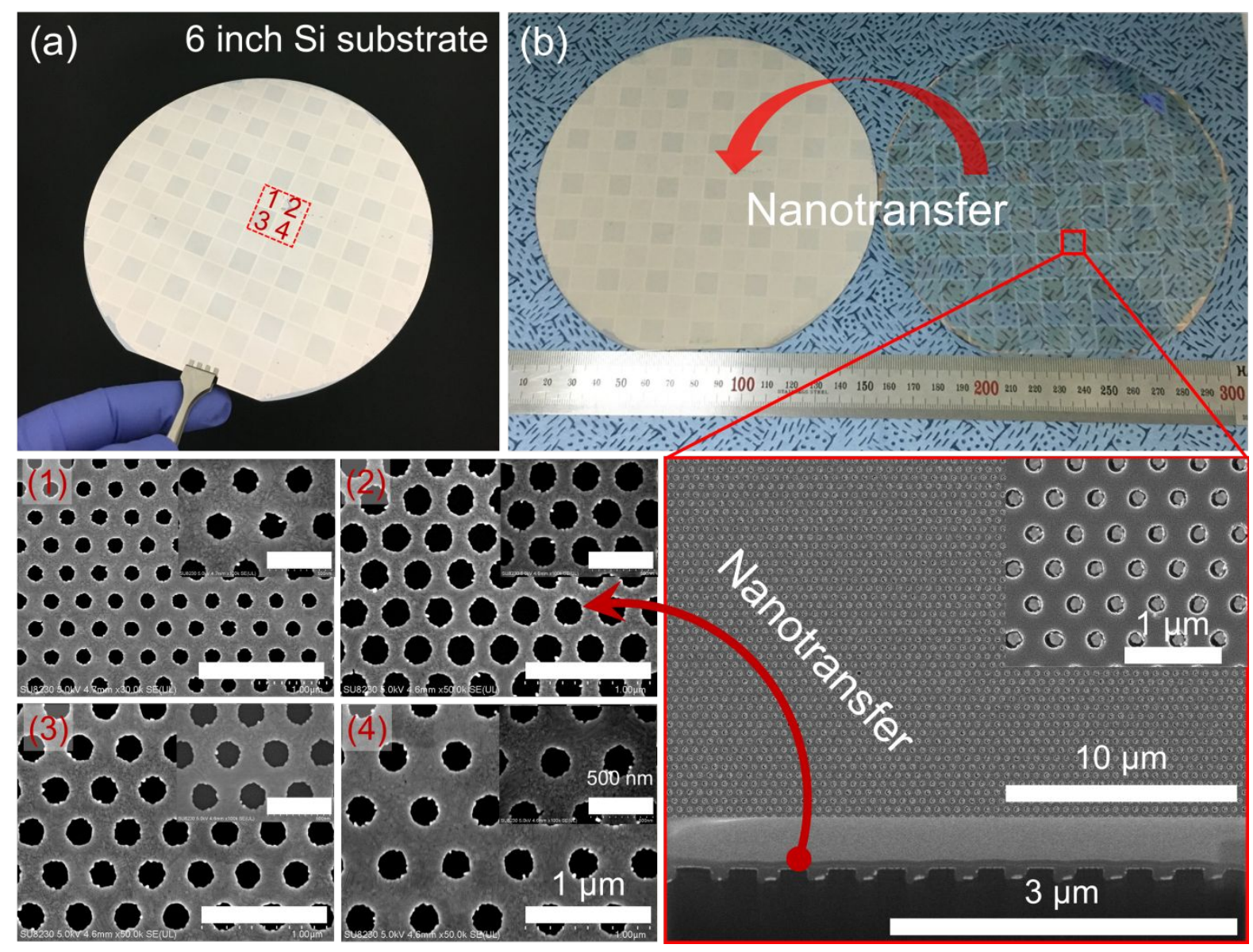

Figure S12. Photographs and top view SEM images of the Au nanomeshes with a diameter of $200 \mathrm{~nm}$ and different pitches that were transfer-printed onto a 6-inch Si substrate.
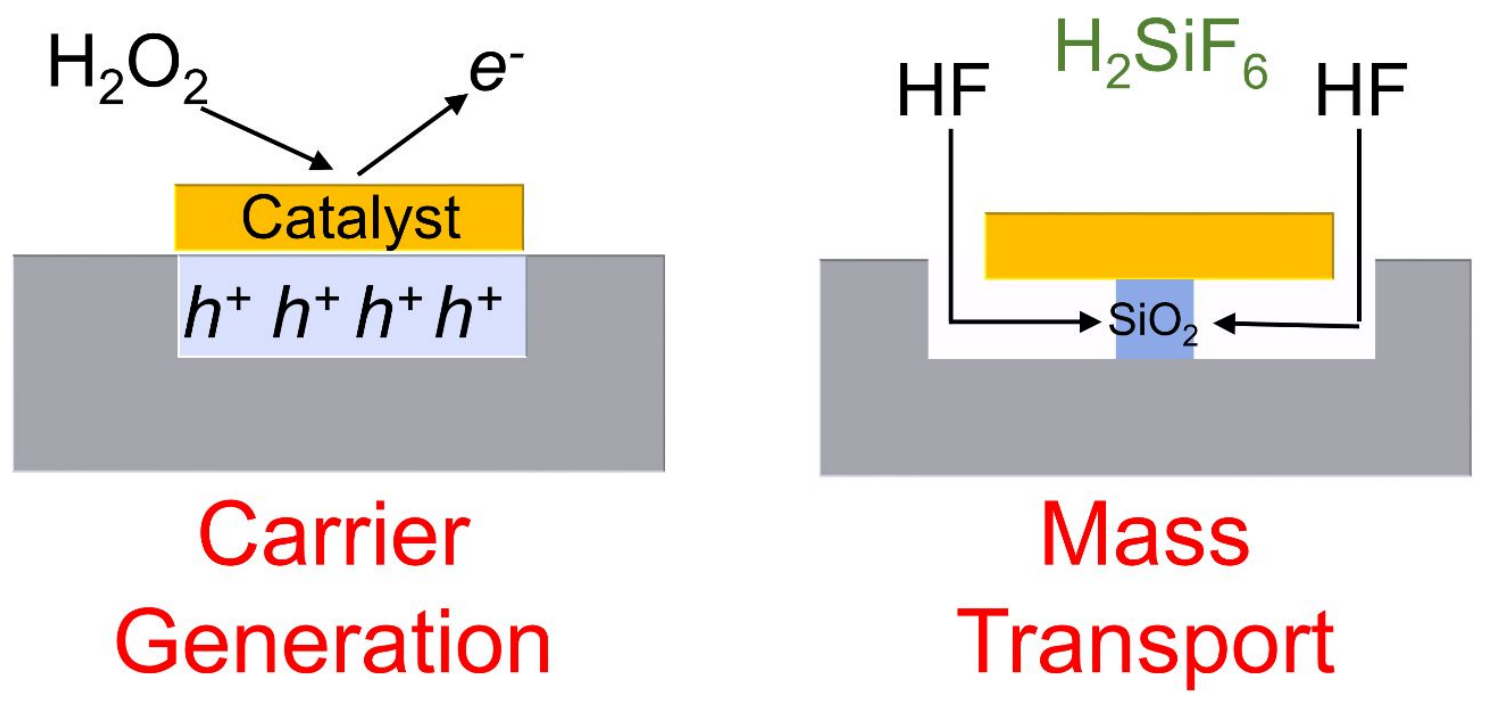

Figure S13. Mechanism of MacEtch: Carrier generation and mass transport. 
Mechanism of MacEtch: Figure S13 shows a schematic mechanism of MacEtch process. After the transfer printing of the Au nanopatterns onto a 6-inch Si substrate, the substrate was submerged in an etching solution consisting of $\mathrm{H}_{2} \mathrm{O}_{2}$ and $\mathrm{HF}$. The Au served as a local cathode to catalyze the reduction of the $\mathrm{H}_{2} \mathrm{O}_{2}$, producing holes without being consumed (carrier generation). These holes migrated into the valence band of $\mathrm{Si}$ to create an ionic material $\left(\mathrm{H}_{2} \mathrm{SiF}_{6}\right)$ that was soluble in HF. The acid dissolution process occurred laterally from the boundaries of the Au patterns (mass transport). Once the ionised semiconductor was removed, a fresh $\mathrm{Au} / \mathrm{Si}$ interface was established. Under controlled etching conditions, the MacEtch reactions occurred only at the interface between the metal and the semiconductor. Consequently, the metal layer descended as the underlying semiconductor was eroded; thus, the $\mathrm{Au}$ functioned as a digger or drill that penetrated into the $\mathrm{Si}$, resulting in the formation of $3 \mathrm{D}$ Si nanostructures. ${ }^{6}$ 

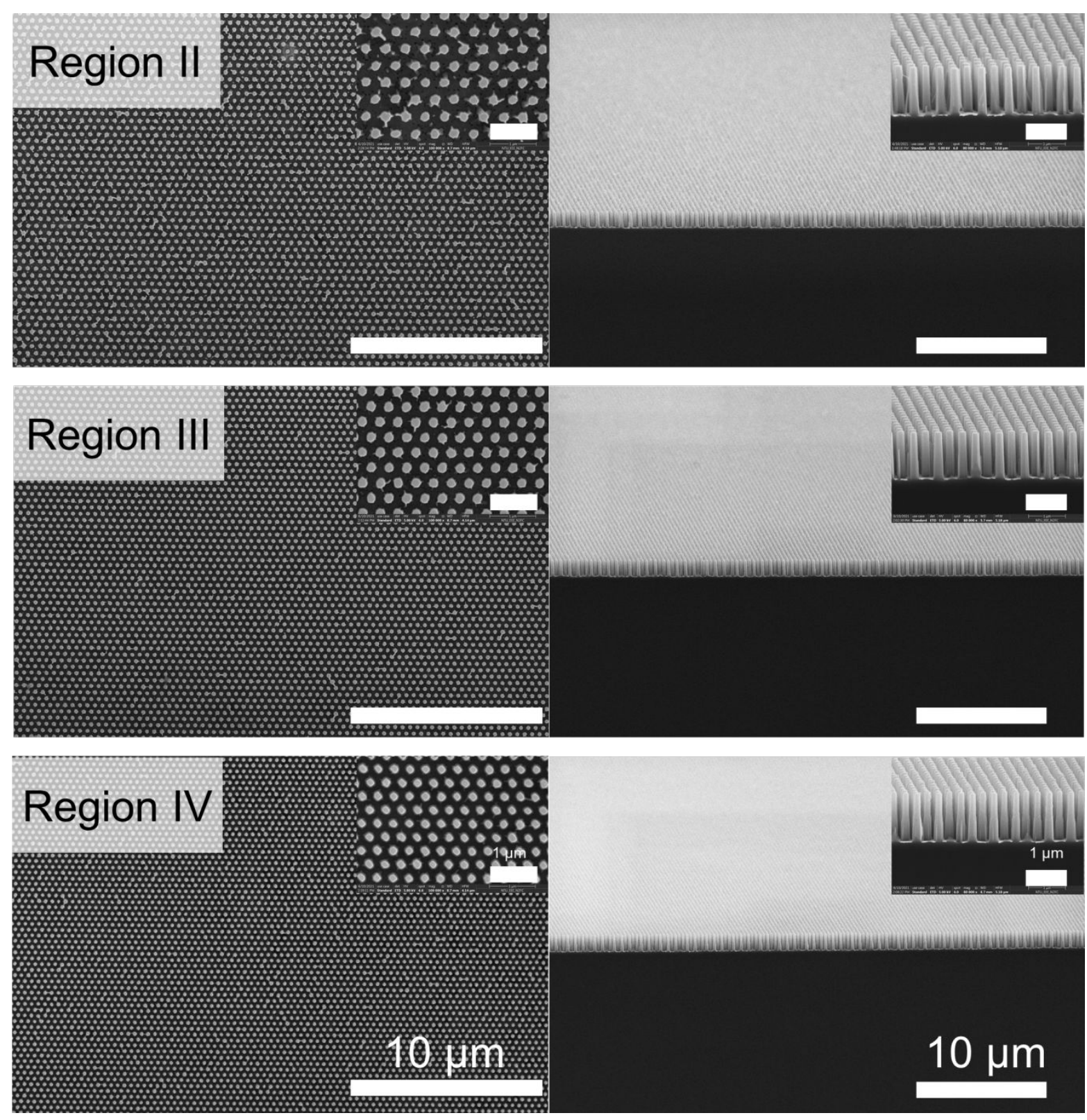

Figure S14. SEM images (top-view, tilted images, and cross-section) of Si nanowires after etching for 10 minutes at the region II, III, IV, demonstrating excellent uniformity. Note that all images share the same scale bar. 

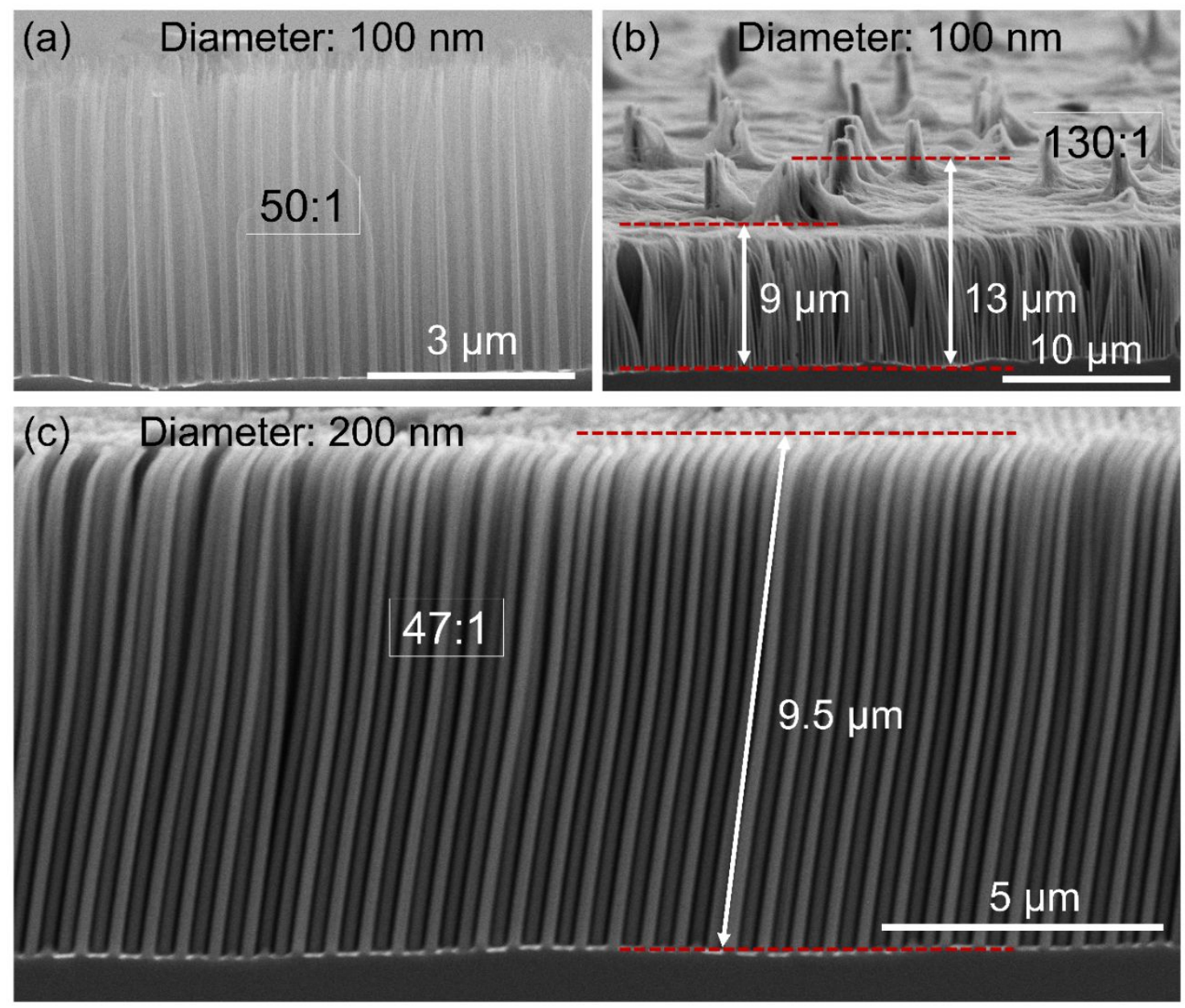

Figure S15. Cross-sectional SEM images of Si nanowires with extremely high aspect ratios (HARs). (a) Si nanowires with a diameter of $100 \mathrm{~nm}$ and HAR of approximately 50:1. (b) Si nanowires with a diameter of $100 \mathrm{~nm}$ and HAR of approximately 130:1. (c) Si nanowires with a diameter of $200 \mathrm{~nm}$ and HAR of approximately $47: 1$. 
(a)

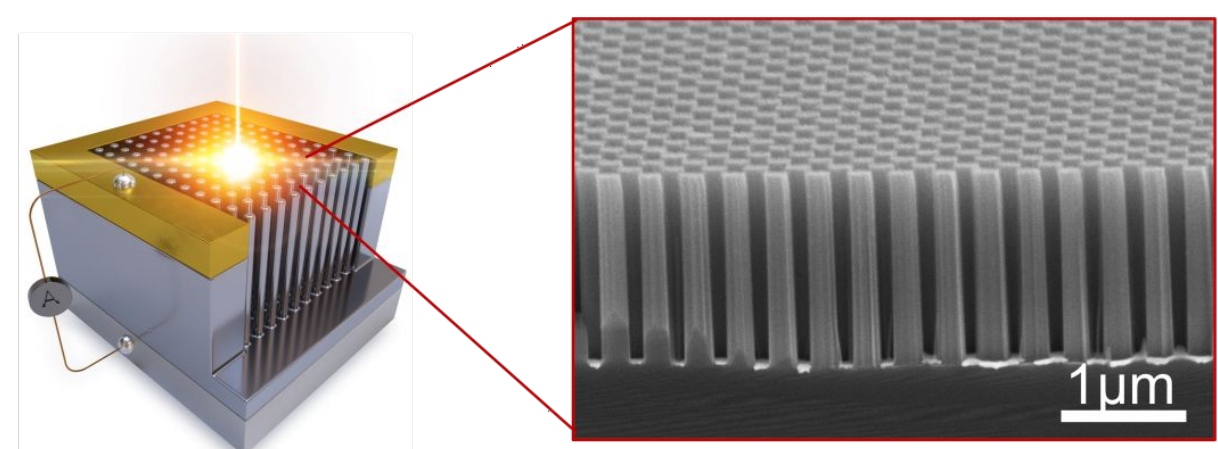

(b)

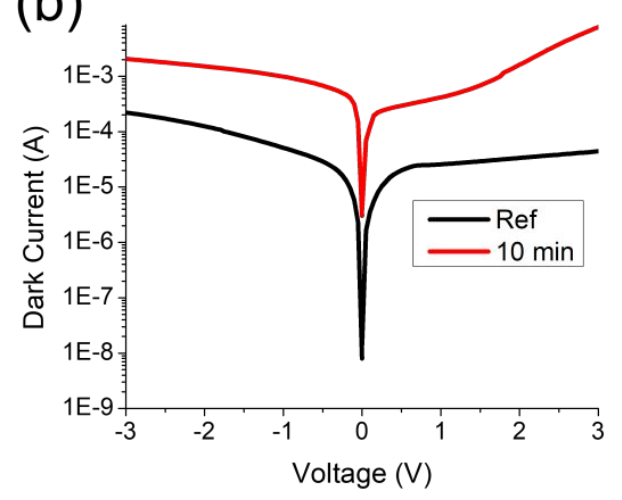

(c)

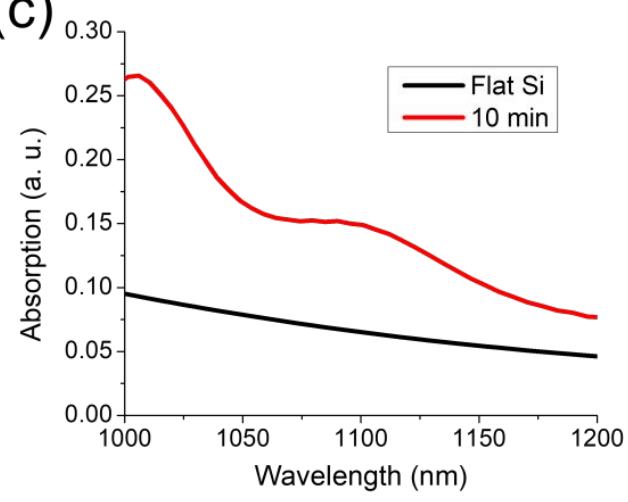

Figure S16. (a) Three-dimensional (3D) schematic image of a Si NW photodetector. The right image represents the SEM image of Si NWs MacEtched for 10 min. (b) $I_{\text {dark }}-V$ characteristic for reference and Si NW photodetectors. (c) Calculated absorption spectra for the flat Si and Si NWs. 
(a)

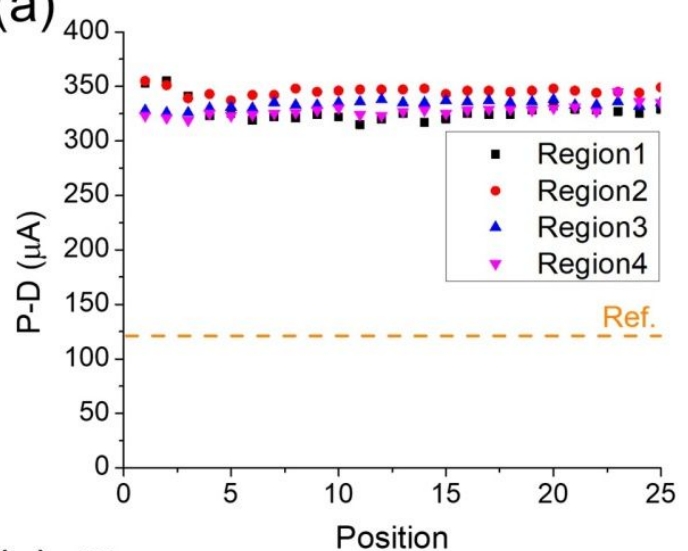

(c)

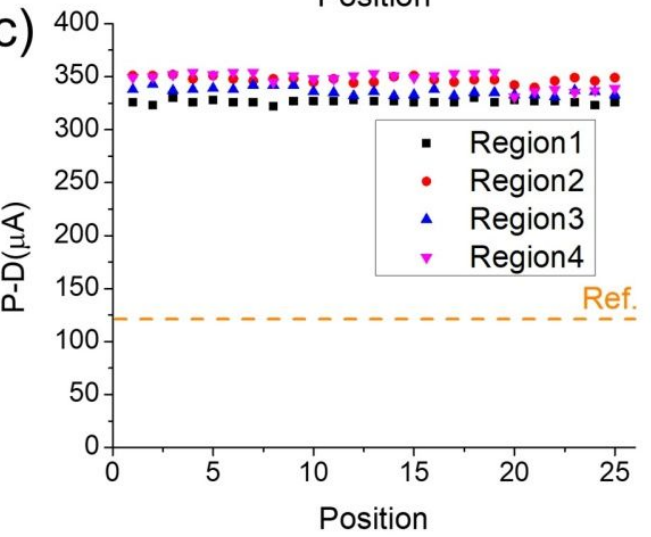

(e)

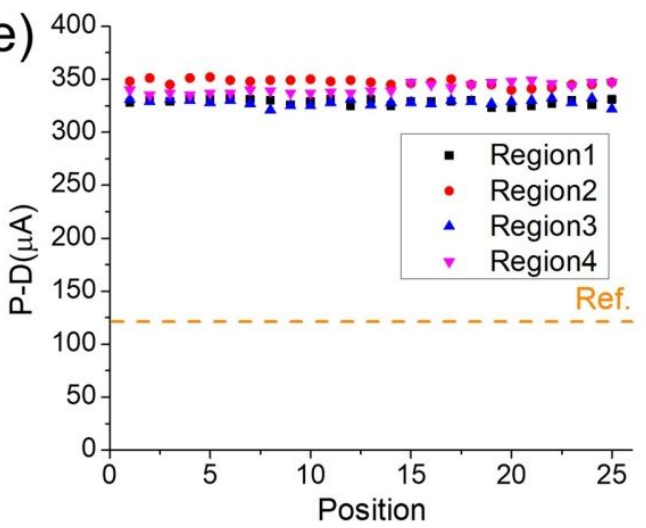

(b)
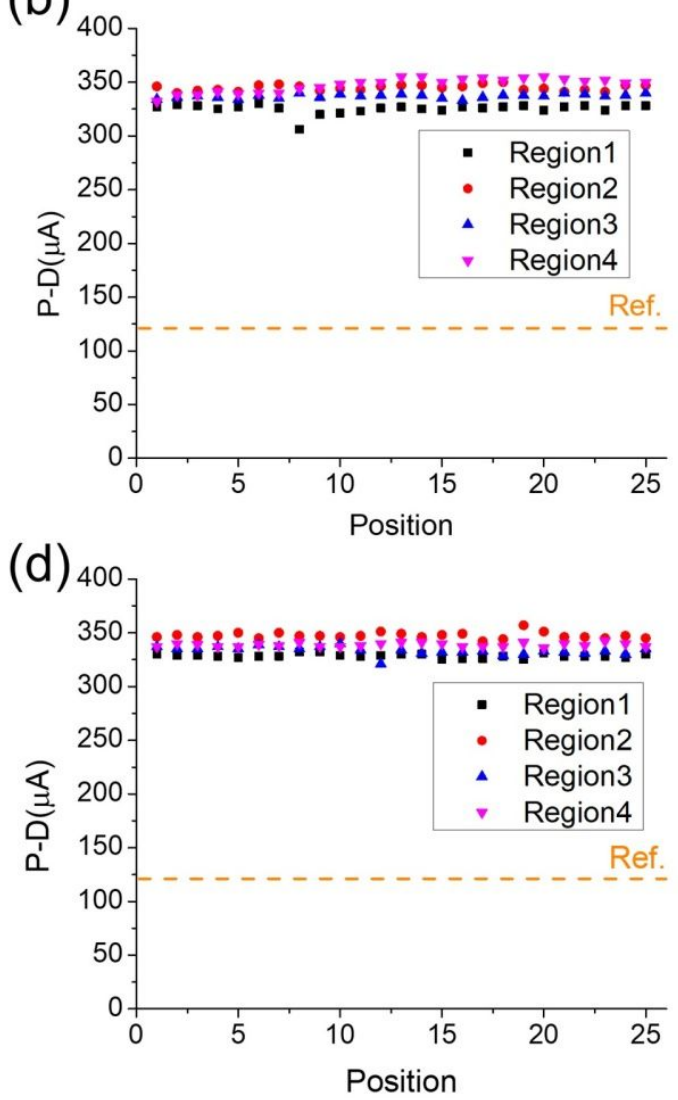

Figure S17. The responsivity of 6-inch wafer scale Si NWs on each region with respect to each position for 1 st to 5 th time measurements (a)-(e). 
Si NW-based photodetectors under the visible light illumination: Most of the Si photodetectors are used in the visible range. However, in this work, we intentionally selected the near-infrared (NIR) range for the photo-response measurement. According to Ref. 7, the responsivity of the Si NW arrays decreases at a short wavelength owing to the shallow photon penetration depth in the visible range. The photons with the shorter wavelength are mainly absorbed at the surface, while the photons with longer wavelength penetrate deeper into the Si NW arrays.

The photo-excited carriers on the surface require relatively long time to reach the electrodes. Therefore, most of them recombine before reaching the electrodes due to the reduced effective carrier lifetime in the Si NW arrays. ${ }^{8}$ Experimentally, we used the photodetectors to measure the photo-response in the visible range using the $532 \mathrm{~nm}$ laser. However, no noticeable change was observed between $\mathrm{I}_{\text {dark }}$ and $\mathrm{I}_{\text {photo }}$.

In order to address this issue, we removed remaining Au using an Au-etchant. Subsequently, we deposited the Ti/TiN/Al metal stacks directly on top of the Si NW arrays with the interdigitated electrode shape, as shown in Figure 18(a) and (b), which exhibit the advantage of fast carrier collection path. The $532 \mathrm{~nm}$ laser was used for the photo-response experiment. Figure 19(a) and (b) represent the $\mathrm{I}-\mathrm{V}$ curves and the responsivity as a function of voltage, respectively, for Si NW and Si planar photodetectors. These measurements confirm that the responsivity is enhanced by a factor of 1.6, as shown in Figure 19(b). However, the extra fabrication steps, such as Au removal and sonication for the lift-off process, may deform the NW arrays and their properties. ${ }^{9}$ Therefore, we used the Si NW array right directly after the MacEtch process to compare the properties of the Si NW arrays fabricated using the CF-nTP and MacEtch processes. 
(a)

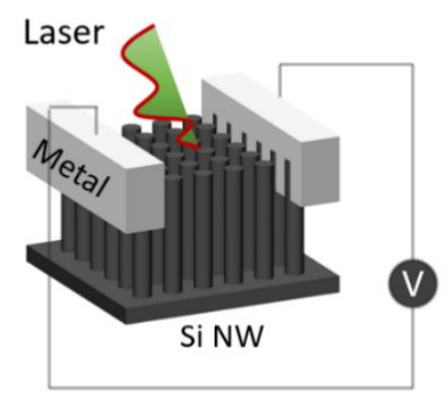

\section{(b)}

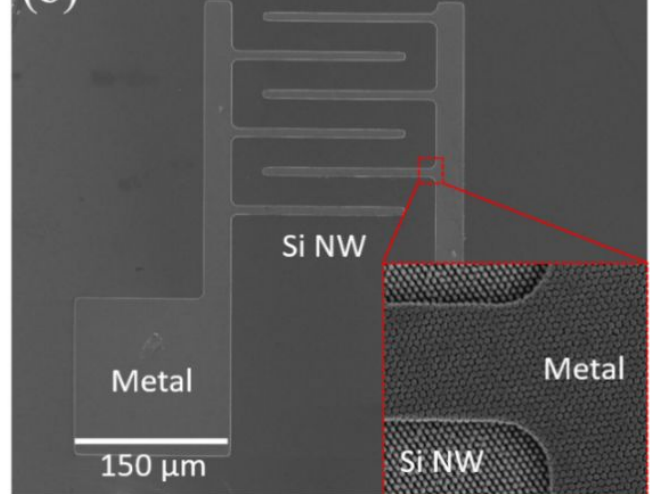

Figure S18. (a) Schematic representation of the photodetector with interdigitated electrodes. (b) SEM image for the top-view of the photodetector. Inset shows the magnified image for the top surface.

(a)

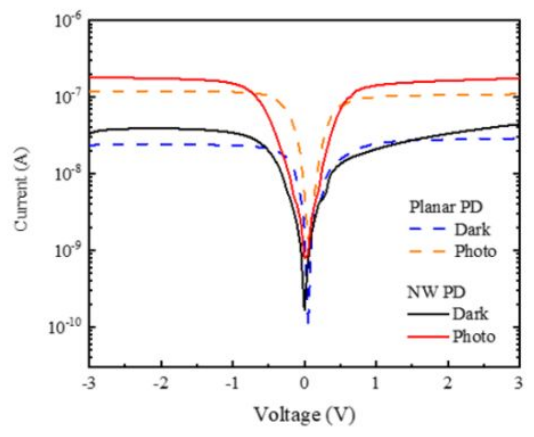

(b)

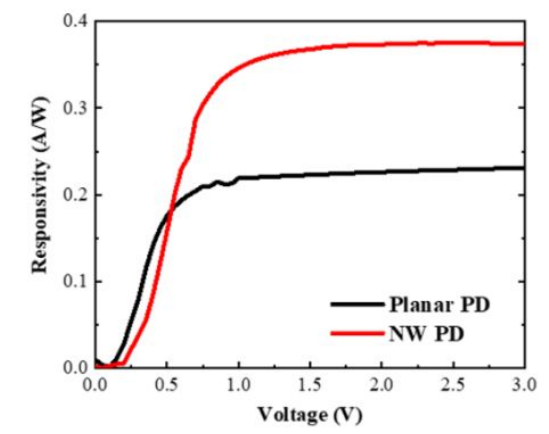

Figure S19. (a) I-V curves $\left(\mathrm{I}_{\mathrm{dark}}-\mathrm{V}\right.$ and $\left.\mathrm{I}_{\text {photo }}-\mathrm{V}\right)$ of the photodetectors using planar $\mathrm{Si}$ and $\mathrm{Si}$ NW arrays.

(b) Responsivity for the planar and Si NW photodetectors as a function of voltage. 
References

1. Love, J. C.; Estroff, L. A.; Kriebel, J. K.; Nuzzo, R. G.; Whitesides, G. M. Self-Assembled Monolayers of Thiolates on Metals as a Form of Nanotechnology. Chem. Rev. 2005, 105, 1103-1170.

2. Zhao, Z. J.; Hwang, S. H.; Jeon, S.; Jung, J.-Y.; Lee, J.; Choi, D.-G.; Choi, J.-H.; Park, S.-H.; Jeong, J.-H. Effects of Polymer Surface Energy on Morphology and Properties of Silver Nanowire Fabricated via Nanoimprint and E-Beam Evaporation. Appl. Surf. Sci. 2017, 420, 429-438.

3. Jiang, Q.; Zhang, S.; Zhao, M. Size-Dependent Melting Point of Noble Metals. Mater. Chem. Phys. 2003, 82, 225-227.

4. Castro, T.; Reifenberger, R.; Choi, E.; Andres, R. P. Size-Dependent Melting Temperature of Individual Nanometer-Sized Metallic Clusters. Phys. Rev. B. 1990, 42, 8548.

5. Zhang, M.; Efremov, M. Y.; Schiettekatte, F.; Olson, E. A.; Kwan, A. T.; Lai, S. L.; Wisleder, T.; Greene, J. E.; Allen, L. H. Size-Dependent Melting Point Depression of Nanostructures: Nanocalorimetric Measurements. Phys. Rev. B. 2000, 62, 10548.

6. Huang, Z., Geyer, N., Werner, P., De Boor, J., \& Gösele, U. Metal-Assisted Chemical Etching of Silicon: A Review: In Memory of Prof. Ulrich Gösele. Adv. Mater. 2011, 23, 285-308.

7. Kim, K.; Ki, B.; Bong, H.; Choi, K.; Oh, J. Ultralow Optical and Electrical Losses via Metal-Assisted Chemical Etching of Antireflective Nanograss in Conductive Mesh Electrodes. Adv. Opt. Mater. 2020, $8,2000143$.

8. Oh, J.; Oh, H.-C.; Branz, H. M. An 18.2\%-Efficient Black-Silicon Solar Cell Achieved through Control of Carrier Recombination in Nanostructures. Nat. Nanotechnol. 2012, 7, 743-748.

9. Dai, H.; Dai, T. Y.; Li, M. C. Spotlight on Ultrasonic Fracture Behavior of Nanowire: Their SizeDependent Effect and Prospect for Controllable Functional Modification. RSC Adv. 2016, 6, 72080. 